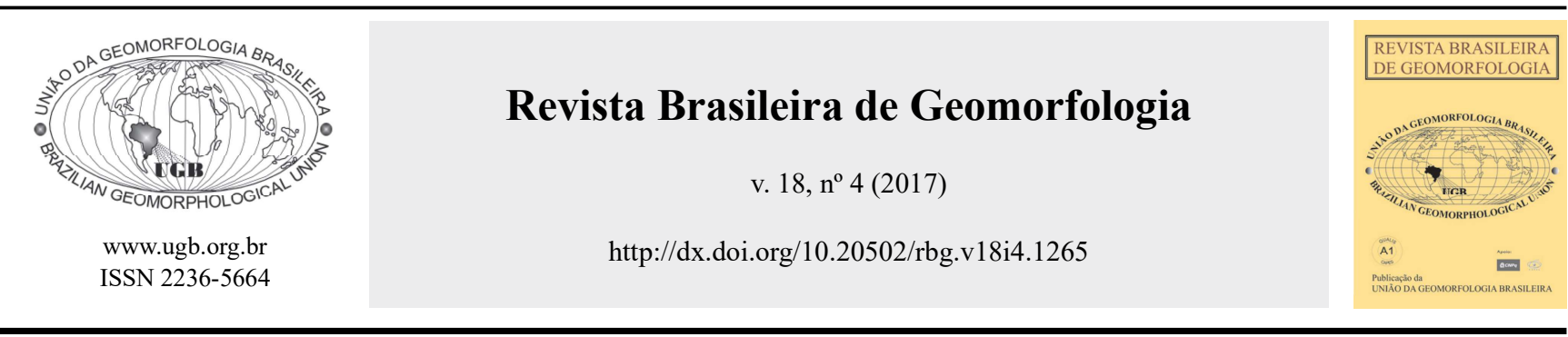

\title{
FORMAÇÃO DE ESCARPAS DE TEMPESTADE E SEU RECONHECIMENTO NO REGISTRO GEOLÓGICO: PLANÍCIE COSTEIRA DE MARICÁ (RIO DE JANEIRO, BRASIL)
}

\section{STORM SCARP FORMATION AND ITS RECOGNITION IN THE GEOLOGICAL RECORD: MARICÁ COASTAL PLAIN (RIO DE JANEIRO, BRAZIL)}

\author{
Maria Augusta Martins da Silva \\ Departamento de Geologia e Geofisica, Universidade Federal Fluminense
} Av. Gal. Milton Tavares de Souza, s/n ${ }^{o}$, Niterói, Rio de Janeiro. CEP: 24210-346. Brasil Email: mariaaugustasilva0@gmail.com

André Luiz Carvalho da Silva

Departamento de Geografia, Universidade do Estado do Rio de Janeiro Rua Francisco Portela, 1470, São Gonçalo, Rio de Janeiro. CEP 24435-005. Brasil

Email: andrelcsilvageouerj@gmail.com

\author{
Carolina Pereira Silvestre \\ Departamento de Geologia e Geofisica, Universidade Federal Fluminense
} Av. Gal. Milton Tavares de Souza, s/n ${ }^{\circ}$, Niterói, Rio de Janeiro. CEP: 24210-346. Brasil Email: carolinasilvestregeouff@gmail.com

\section{Informações sobre o Artigo \\ Recebido (Received): \\ 13/05/2017 \\ Aceito (Accepted): \\ 21/07/2017}

\section{Palavras-chave:}

Escarpas de Tempestades;

Paleoescarpas; Paleoambientes; Quaternário; Maricá/RJ.

\section{Keywords:}

Storm Scarps; Paleoscarps; Paleoenvironments; Quaternary; Maricá/RJ.

\begin{abstract}
Resumo:
As escarpas de tempestade são feições marcantes em uma praia. Elas apresentam morfologias diagnósticas de seu modo de formação e, devido à possibilidade de preservação, podem ser utilizadas em estudos visando à reconstituição paleoambiental. Essas feições costeiras se formam quando ondas mais altas e de maior energia promovem o corte das camadas de sedimentos que formam as bermas causando o recuo das mesmas. O resultado é: (1) a formação de uma escarpa, cuja altura depende da altura das ondas; (2) o truncamento das camadas plano-paralelas horizontais a sub-horizontais das bermas; (3) a criação de uma superfície planar ou côncava inclinada para o mar na frente da escarpa. Nas últimas décadas, estudos sobre a estratigrafia e as sequências sedimentares quaternárias de áreas costeiras vêm utilizando cada vez mais o ground penetrating radar (GPR), no Brasil e no mundo. Em alguns casos, as imagens de GPR revelam refletores que correspondem a antigas superfícies relativas às escarpas de tempestade, facilmente correlacionadas com as observadas no ambiente moderno. Na região de Maricá (Rio de Janeiro), trabalhos realizados para caracterizar a planície costeira atual, bem como, aqueles conduzidos para desvendar o Quaternário dessa área, mostraram o papel importante das escarpas de tempestade e das superfícies de
\end{abstract}


truncamento associadas como indicadores de antigas praias nas sequências sedimentares mapeadas. Assim, foi possível visualizar as antigas posições das praias formadas durante períodos de nível do mar mais altos que o atual e a subsequente progradação da linha de costa através do reconhecimento de uma sequência de paleoescarpas de tempestade migrando através da planície costeira até alcançar posições próximas à escarpa de tempestade atual.

\begin{abstract}
:
Storm scarps are conspicuous beach morphologies. They show diagnostic features that help the identification of their mechanism of formation, and since they present potential for preservation, they can be useful for paleoenvironmental studies. Storm scarps form when high waves cut the berms and cause their retreat. The result is: (1) the formation of a scarp whose height depends on the wave height; (2) the truncation of the horizontal to sub-horizontal plane-parallel layers of the berm; (3) the creation of a planar or concave up surface inclined to the sea. In the last decades, there has been an increase of studies, in Brazil and worldwide, about the Quaternary coastal stratigraphy and sedimentary sequences using ground penetrating radar (GPR) techniques. In several cases, reflectors on the GPR images are easily correlated to modern storm scarps. In Maricá (Rio de Janeiro state), surveys carried out to characterize the coastal plain, have show the important role of the storm scarps and the associated truncation surfaces as evidences for the recognition of old beaches on the mapped sedimentary sequences. Thus, it has been possible to determine: (1) previous beach positions formed during times of higher sea level; (2) a phase of coastal progradation identified through a succession of storm paleoscarps that migrated across the coastal plain until they reached a position near today's beach storm scarp.
\end{abstract}

\section{Introdução}

Uma praia pode ser caracterizada como uma faixa de areia com uma morfologia altamente dinâmica, resultado principalmente da ação das ondas e também dos ventos, das correntes e da maré. A praia se caracteriza como o local onde a interação entre os sedimentos e os processos costeiros ocorrem em ciclos que variam de horas (marés), meses (sazonal: verão, inverno), séculos a milhares de anos (variações do nível do mar, por exemplo). A praia se estende desde a zona de arrebentação mais externa das ondas (limite externo ou marinho da praia), até o local de alcance máximo das ondas de tempestades mais frequentes (limite interno ou continental da praia) (FRIEDMAN e SANDERS, 1978). Geralmente, nesse local se observam falésias, dunas ou escarpas de tempestades que são esculpidas na areia da praia pelas ressacas.

Uma praia pode apresentar várias feições morfológicas típicas de sua dinâmica, tais como, barras, canais, cúspides de praia, bermas e escarpas, entre outras. Uma escarpa é um declive íngreme ou uma falésia em miniatura formada pela ação das ondas em frente à berma, em uma praia (RAMSON HOUSE DICTIONARY, 2017). O objetivo deste trabalho é caracterizar as escarpas de tempestade e apresentar sua importância para a identificação de antigas praias no registro geológico. A intenção é mostrar as características das escarpas de tempestade, tanto em superfície quanto em subsuperfície, e com isso corroborar com as interpretações que vem sendo realizadas em feições semelhantes observadas em imagens de georadar (GPR-ground penetrating radar) (SILVA, 2011; SILVA et al., 2014b; SILVESTRE, 2013 e SILVESTRE et al., 2015). As imagens obtidas na planície costeira de Maricá apresentam em determinados locais, segundo esses autores acima citados, uma estratigrafia representada por camadas de areia com estruturas similares àquelas observadas nas escarpas de tempestade das praias da região. Assim, com essa correlação é possível reconhecer antigas praias no registro geológico e a localização das mesmas indica o comportamento da costa ao longo do tempo (com fases de progradação e retrogradação). Sendo, portanto, uma importante ferramenta para o reconhecimento da paleogeografia e das posições relativas do nível do mar, facilitando assim a compreensão da evolução de uma determinada região.

Neste trabalho, serão apresentados exemplos do litoral de Maricá (Rio de Janeiro), especificamente da praia de Itaipuaçu e da área de restinga conhecida como Área de Proteção Ambiental (APA) de Maricá (Figura 1). A planície costeira de Maricá se estende desde a Serra da Tiririca, junto à Pedra do Elefante, até Ponta Negra, no total de aproximadamente 37 quilômetros de extensão (Figura 1). De modo geral, a região costeira de Maricá é formada por uma barreira pleistocênica (a 
mais interna) e outra holocênica, separadas por uma área baixa, alongada e às vezes alagadiça, representativa de antigas lagunas colmatadas (SILVA, 2011; SILVA et al., 2014b; SILVA et al., 2014c). Na retaguarda desses sistemas barreira-laguna encontra-se a Lagoa de Maricá, juntamente com outras de dimensões menores (Figura 1). As praias da região são de alta energia, em particular a de Itaipuaçu (SILVA, 2006; SILVA et al., 2008a; PARDAL, 2009), onde as ondas são comumente altas e as ressacas podem ocasionar, com certa frequência e em diversos trechos, o fenômeno de sobrelavagem (overwash) e formação de leques de arrombamento (SILVA et al., 2008b), e em outros locais a formação de escarpas. Neste trecho do litoral, que tem como característica marcante a granulometria grossa dos sedimentos formadas por areias grossas e cascalhos, o perfil de praia é muito dinâmico, com intensa variação entre o inverno, após ressacas, quando os perfis são mais íngremes e escarpados, e o perfil de verão com bermas pronunciadas (SILVA et al., 2008a; PARDAL, 2009). Escarpas de tempestades são comuns nessa praia (Figura 2 A e B). Suas características e modo de formação são aqui discutidas, com o objetivo de realçar a importância dessas feições como elementos diagnósticos para o ambiente de praia aplicável no registro geológico para fins de reconstrução paleoambiental.
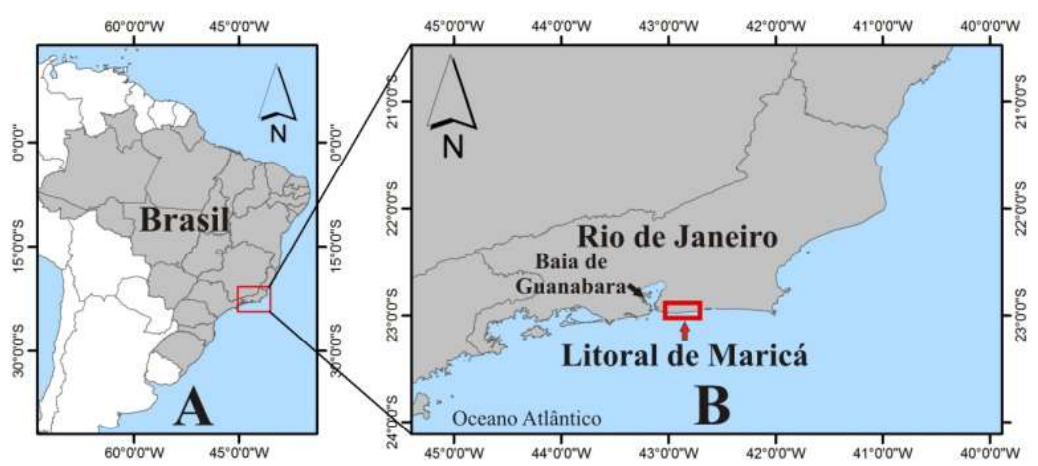

\section{Legenda}

Praia

Depósitos Quaternários

(DRM, 1977)

Embasamento Pré-Cambriano
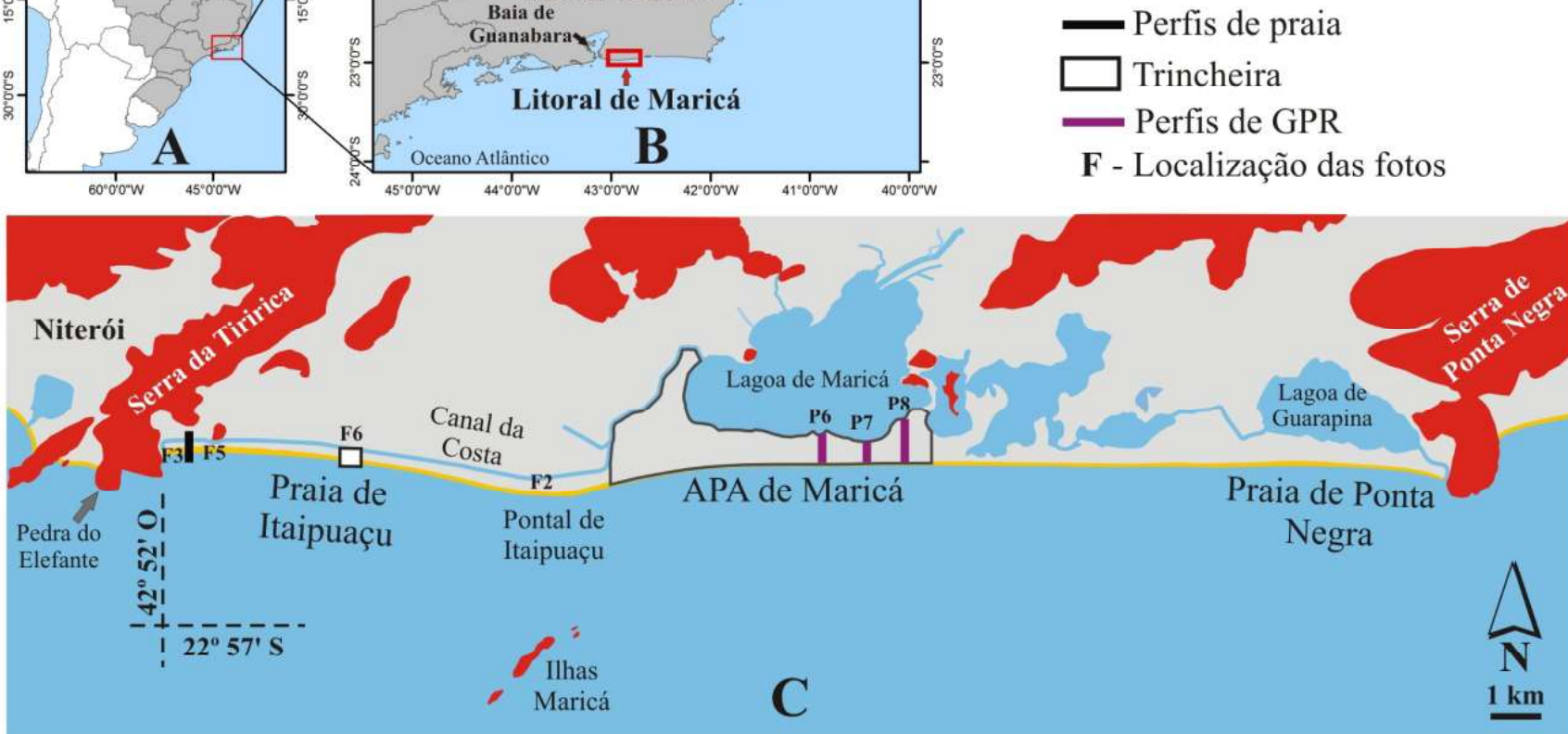

Figura 1 - (A, B) Localização da área de estudos no estado do Rio de Janeiro, sudeste do Brasil.(C) Principais características geomorfológicas do litoral de Maricá, com a área de estudos na porção oeste (Praia de Itaipuaçu) e central (APA de Maricá) da planície costeira. Mapa Geológico, DRM-RJ (1977).

\section{Metodologia}

Neste trabalho são utilizados dados obtidos em diferentes momentos e em diferentes projetos de pesquisa conduzidos pelos autores, todos com a proposta de contribuir para o melhor conhecimento da geologia e geomorfologia costeira.

Serão aqui apresentados e discutidos registros fotográficos, perfis topográficos, trincheiras de praia e imagens de GPR. Os perfis topográficos foram realizados na praia de Itaipuaçu (Figura 1), utilizando-se o método das balizas de Emery (1961), o qual foi empregado por mais de uma década no litoral de Maricá, e permitiu o reconhecimento da dinâmica dessa praia e o importante papel das ressacas nesse trecho do litoral do Rio de Janeiro (SILVA, 2006; SILVA et al., 2008a). As trincheiras foram realizadas no meio do arco praial em Itaipuaçu, na década de 1970 (SILVA, 1972). Elas foram abertas a 
partir do pós-praia, passando pela escarpa de tempestade e terminando na vegetação de restinga, com uma profundidade variando entre 1,5 e 2 metros. Uma das faces da trincheira foi fotografada, desenhada e os ângulos de mergulho dos estratos medidos; assim, que foi possível a identificação de feições pretéritas, tais como bermas, escarpas, superfícies de truncamento e, a partir disso, os eventos responsáveis e a dinâmica do litoral ao longo do tempo. As imagens de GPR foram obtidas em 2012, ao longo de perfis transversais à linha de praia na barreira holocênica, com a antena de $400 \mathrm{MHz}$. As imagens representam uma seção sedimentar de até 10-15 metros de espessura (SILVESTRE, 2013; SILVESTRE et al., 2015). Neste artigo, porém, iremos focalizar os cerca de 2,5 a 3,5 metros de espessura do topo da sequência sedimentar, e que corresponde a parte superior do Holoceno (SILVESTRE, 2013; SILVESTRE et al., 2015). A figura 1 apresenta a localização dos dados discutidos neste artigo.
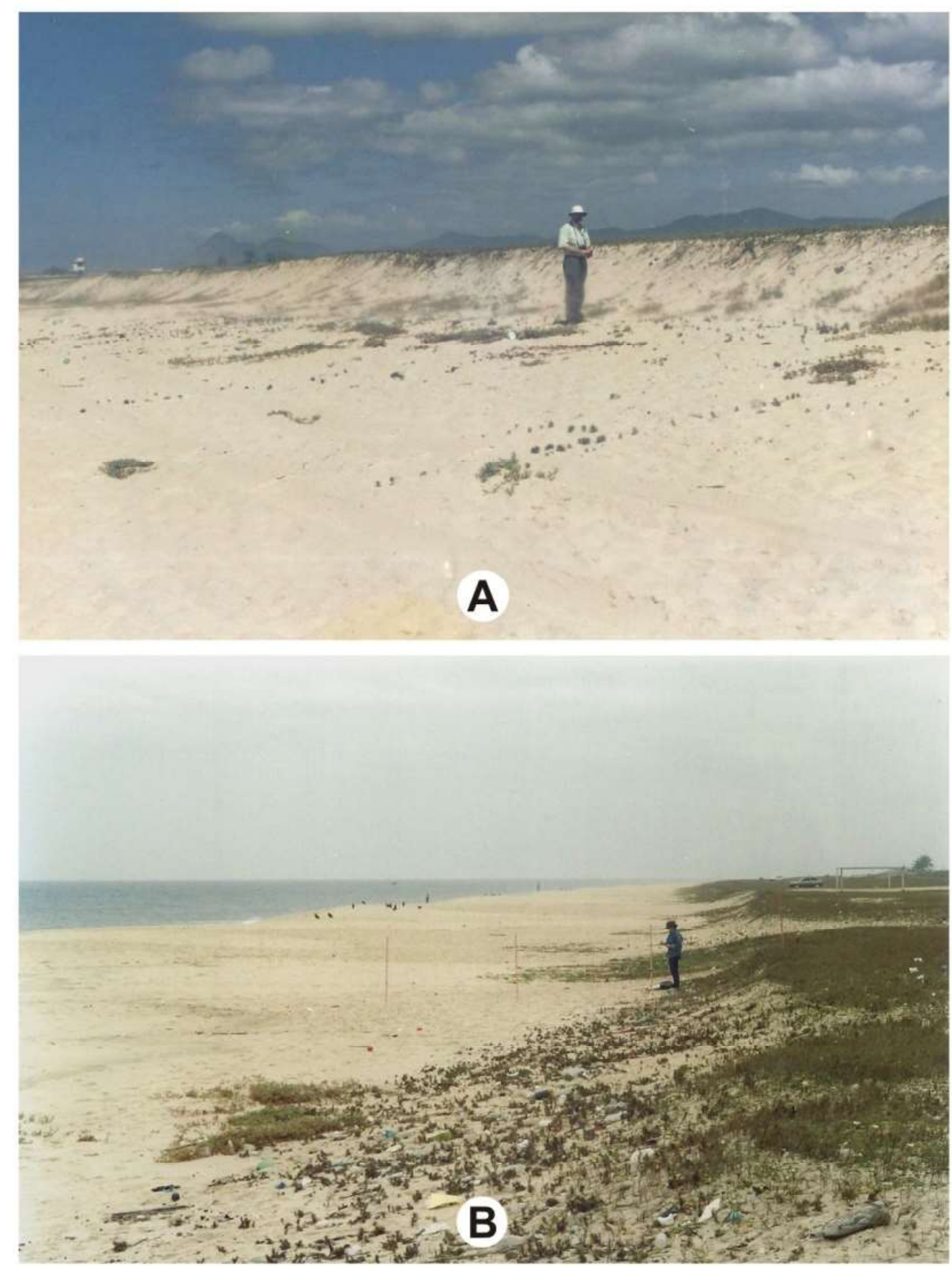

Figura 2 - Escarpa de tempestade (A e B), comum na região de Maricá, marcando o limite interno da praia de Itaipuaçu. Pontal de Itaipuaçu (2000). Fotos: Silva, M.A.M.(A) 2002 e (B) 2004. 


\section{Apresentação dos dados e discussão}

Na parte emersa da praia existe comumente um terraço cuja superfície é horizontal ou pouco inclinada para o continente, formado por areias depositadas pelas ondas. Esta região é denominada berma. No verão, normalmente, a berma (ou bermas) é baixa e larga, enquanto que no inverno ela é mais alta e estreita, uma vez que nesta estação boa parte das areias é transportada para a parte submarina da praia, onde tende a formar barras. Essa mudança é o resultado da dinâmica das ondas, diferente para cada estação do ano. As ondas maiores, associadas às tempestades, mais comuns no inverno, cortam e promovem o recuo das bermas e podem dar origem às escarpas (Figura 3). Por outro lado, as ondas pequenas, mais típicas no verão, retornam com as areias à parte emersa da praia e ampliam as bermas (Figura 4) (BASCOM, 1964). O corte e recuo das bermas deixa como resultado morfológico uma superfície que trunca os estratos das bermas, que pode ser plana ou côncava (Figura 5). Este processo relativo ao corte e recuo das bermas origina as escarpas de tempestade, que se formam quando as ondas cortam e escavam a base da berma causando o solapamento das areias na parte superior desta feição (FRIEDMAN et al. 1992) (Figuras 3A e 5A); o refluxo das ondas carrega essa areia para a parte submarina da praia (Figura 3B), deixando uma superfície lisa e inclinada para o mar (superfície de truncamento). Essas escarpas podem ter faces verticais ou inclinadas, podem ser contínuas por dezenas ou centenas de metros (Figura 2A e B), ou descontínuas, como quando são associadas às correntes de retorno e formação de cúspides (Figura 5A e B). Bonte e Levoy (2015) estudaram uma escarpa artificial com a intenção de contribuir para o entendimento da evolução dessas feições de praia. Também tiveram como intenção compreender o papel importante da berma como elemento natural no controle da redução da razão de recessão de dunas. Para tal, uma berma artificial foi construída em uma praia no litoral da França e com diversos equipamentos os autores acompanharam a erosão da berma e o desenvolvimento de uma escarpa sob condições de mar agitado. Segundo os autores acima citados, o espraiamento das ondas escava a berma criando a escarpa; o processo se repete e aparecem fissuras de tensão no topo da parte frontal da escarpa, paralelas a face da mesma; isso acaba por provocar o desabamento dos sedimentos os quais são depositados na base da escarpa de onde serão removidos pelo refluxo das ondas.

As escarpas de tempestade têm altura controlada pela altura e alcance das ondas e podem ser encontradas em diferentes partes da praia. Assim que, elas tanto podem ser encontradas na passagem entre frente de praia e pós-praia (Figura 5), quanto no limite interno da praia (Figura 2), quando então indicam o alcance máximo das ressacas mais frequentes em um determinado local. No litoral do estado do Rio de Janeiro as ressacas mais intensas ocorrem em intervalos que podem chegar a uma década ou mais, ou cerca de 20 anos conforme Santos (2001) e Santos et al. (2004). Entre as ocorrências dessas ressacas mais intensas, a vegetação de restinga pode se desenvolver cobrindo parcialmente a escarpa de tempestade (Figura 2B).
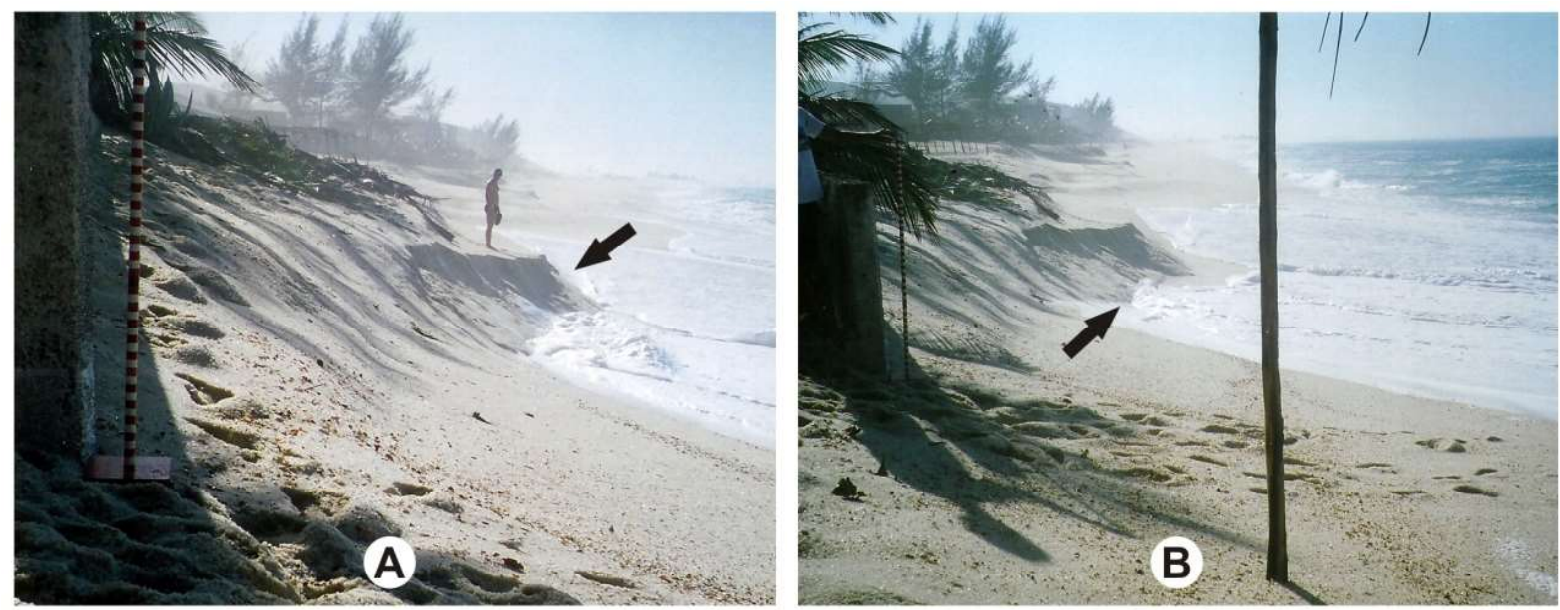

Figura 3 - Corte e recuo da berma e formação de escarpa de tempestade. Observa-se a face íngreme da escarpa à frente de uma berma truncada pela ação das ondas. (A) Ondas cortando a berma e escarpando a praia; (B) refluxo das ondas removendo as areias da berma e transportando as mesmas para a parte submarina da praia. Nessas fotos, pode-se observar claramente os diferentes ângulos de inclinação da superficie de truncamento, que por ser côncava diminui gradualmente a declividade em direção ao mar. Ressaca de 7 de agosto de 2007 na Praia de Itaipuaçu. Fotos tiradas por Silva, M. A. M. (2007). 


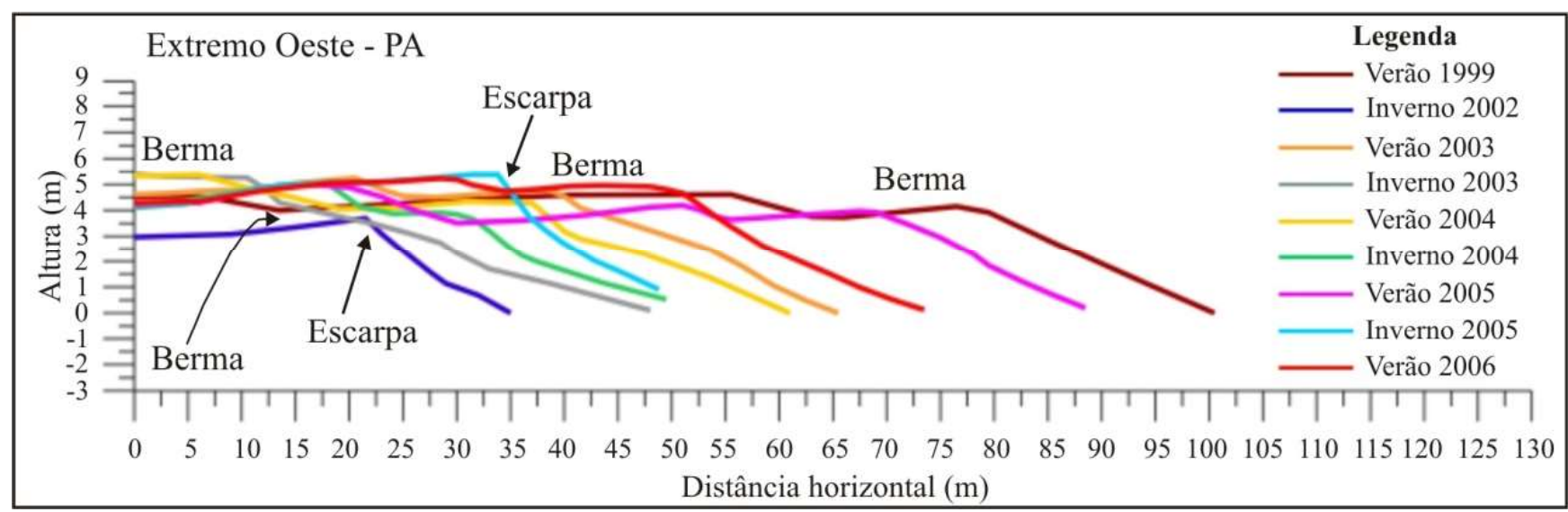

Figura 4 - Perfis de praia coletados sistematicamente desde o inverno de 2002 até o verão de 2006, no extremo oeste da Praia de Itaipuaçu (PA corresponde ao Perfil A de Silva et al., 2008a). Os perfis mostram praias largas com bermas bem desenvolvidas nas estações de verão e praias estreitas com bermas recuadas e escarpas de tempestade nos invernos.
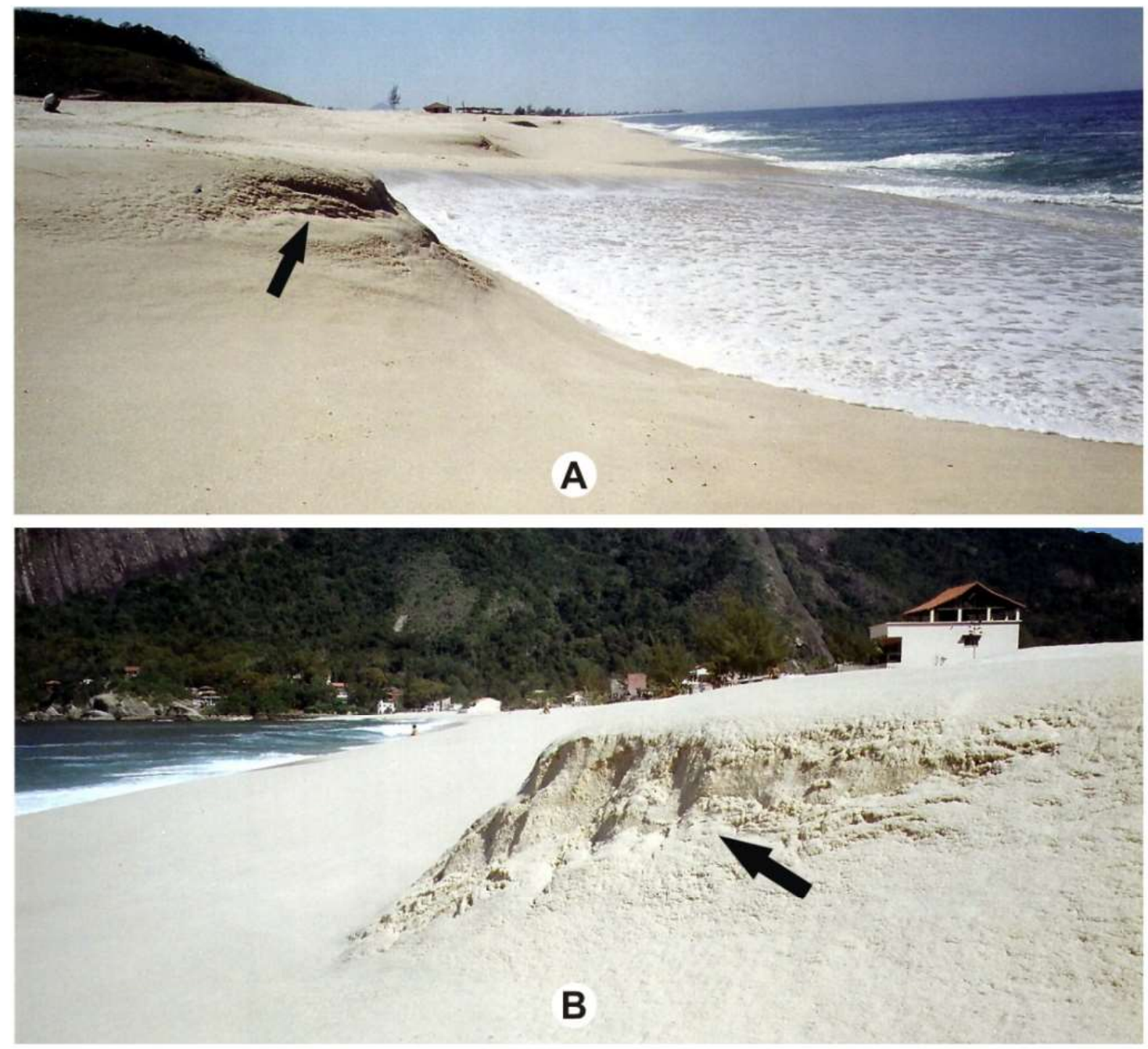

Figura 5 - Escarpa com cerca de 2 metros de altura entre a frente de praia e o pós-praia, associada aos cúspides de praia em Itaipuaçu. (A) Face voltada para oeste, enquanto (B) é a face da escarpa voltada para leste. Observa-se claramente as camadas plano-paralelas horizontais e sub-horizontais que formam a berma truncadas (setas), bem como, a superficie de truncamento, côncava e inclinada para o mar, porém com ângulos diferentes (A). Fotos: Silva, M. A. M. (2007). 
Em situações mais extremas, as ondas de tempestades podem ultrapassar o limite da praia, cortando uma passagem através da barreira e transportando e depositando areias da praia por toda essa região, podendo alcançar até áreas bem internas da retaguarda da barreira, como aquelas marginais de lagunas/lagoas e canais. O depósito sedimentar, geralmente constituído por um sedimento mal selecionado, com areias, seixos e conchas, apresenta uma forma bem característica, denominada leque de arrombamento. Essas feições costeiras estão também presentes na área de estudo (SILVA et al., 2008b) e são de extrema importância para o entendimento da dinâmica local, bem como, são feições diagnósticas para a reconstrução paleoambiental e para o reconhecimento das variações do nível do mar.

As escarpas de tempestade podem ser delineadas pela superfície de truncamento, o que pode ser visto também em subsuperfície. Essas superfícies apresentam ângulos de inclinação diversos: elas podem ser íngremes na parte frontal superior da escarpa; enquanto que, próximo da base da escarpa a inclinação vai diminuindo gradualmente (Figuras 2A e B; 3B; 5A e B). As escarpas de tempestade podem ser observadas em trincheiras e, neste caso, a superfície de truncamento poderá ser a feição mais marcante. Um exemplo disso pode ser visto em uma trincheira na praia de Itaipuaçu (Figuras 1 e 6 ). A trincheira foi aberta a partir do pós-praia, estendendo-se para a restinga, passando pela escarpa de tempestade (limite atual da praia) (Figura 2), alcançando algumas dezenas de metros e cerca de 1,5 a 2 metros de profundidade. Duas superfícies de truncamento podem ser observadas na trincheira (Figura 6 - as setas indicam essas feições): a superficie de truncamento mais à frente (em direçãoà praia atual) encontra-se muito próxima a atual escarpa de tempestade e se prolonga até a superfície; a segunda ocorre no cordão litorâneo e em maior profundidade. Ambas mergulham com ângulos de $15-16^{\circ}$ para o mar (Figura 6A e B). Os estratos plano-paralelos sub-horizontais de antigas bermas estão truncados por essas superfícies. Esse conjunto de feições evidencia dois momentos distintos da ação do processo de corte e recuo das bermas, formação de escarpas de tempestade (que neste caso, não aparecem - figura 6), bem como, da posterior reconstrução da berma de uma antiga praia localizada mais para o interior em relação à praia atual.

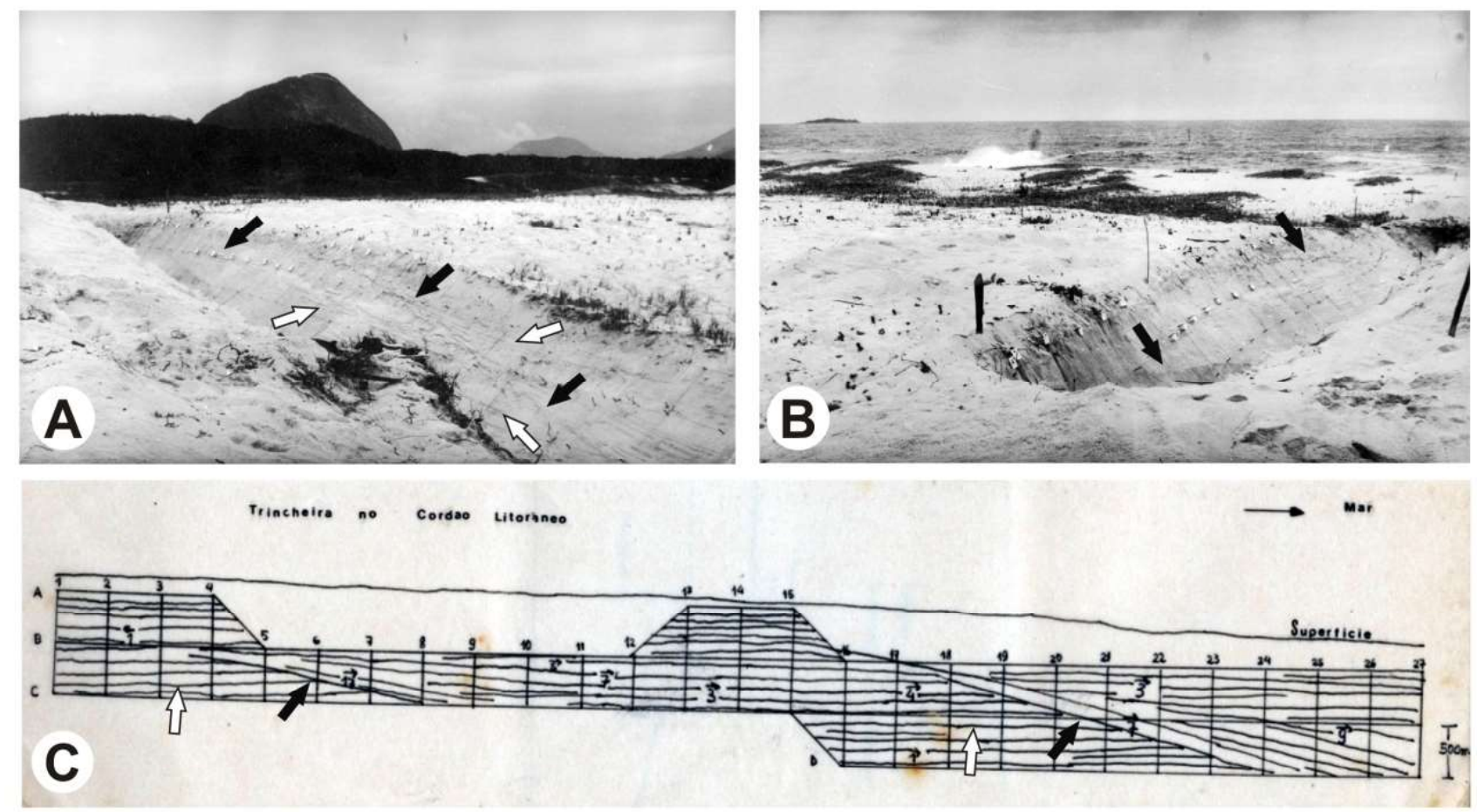

Figura 6-Trincheira aberta aproximadamente no meio do arco de praia em Itaipuaçu na década de 1970, se estendendo desde o pós-praia até a área de restinga, fora dos limites da praia atual. Em (A) vista para o continente, (B) vista para o mar. Duas superficies de truncamento (setas pretas) podem ser observadas na trincheira, e representam o corte e recuo de antigas bermas (setas brancas). Profundidade da trincheira variando de 1,0 a 1,5 metros. (C) Desenho esquemático da trincheira representando as principais camadas, superficies e seus ângulos de mergulho. Fotos tiradas por Silva, M. A. M. (1971). 
Morfologias semelhantes foram observadas em imagens de GPR obtidas na APA de Maricá (Figura 1). Nessas imagens (Figuras 7, 8 e 9) relativas à perfis perpendiculares à linha de costa, observa-se o depósito sedimentar formado durante a evolução dessa planície costeira no Quaternário (SILVA, 2011; SILVESTRE, 2013). Alguns perfis apresentam, em diferentes partes dentro da seção sedimentar e na área correspondente a barreira holocênica, feições similares às escarpas de tempestade e, portanto, interpretados como paleoescarpas (SILVA, 2011; SILVA et al. 2014b; SILVESTRE,
2013; SILVESTRE et al., 2015).

Nas imagens referentes aos perfis 6,7 e 8 de Silvestre (2013) e Silvestre et al.,(2015) (Figuras 7, 8 e 9) foram mapeados refletores inclinados planares ou côncavos semelhantes às superfícies de truncamento. Também foram observados estratos plano paralelos truncados. As dimensões dessas feições são semelhantes às das escarpas de tempestade, bermas e superfícies de truncamento atuais dessa região, podendo chegar a 2,5 metros de altura, compatíveis com as alturas das ondas de ressaca atualmente observadas.

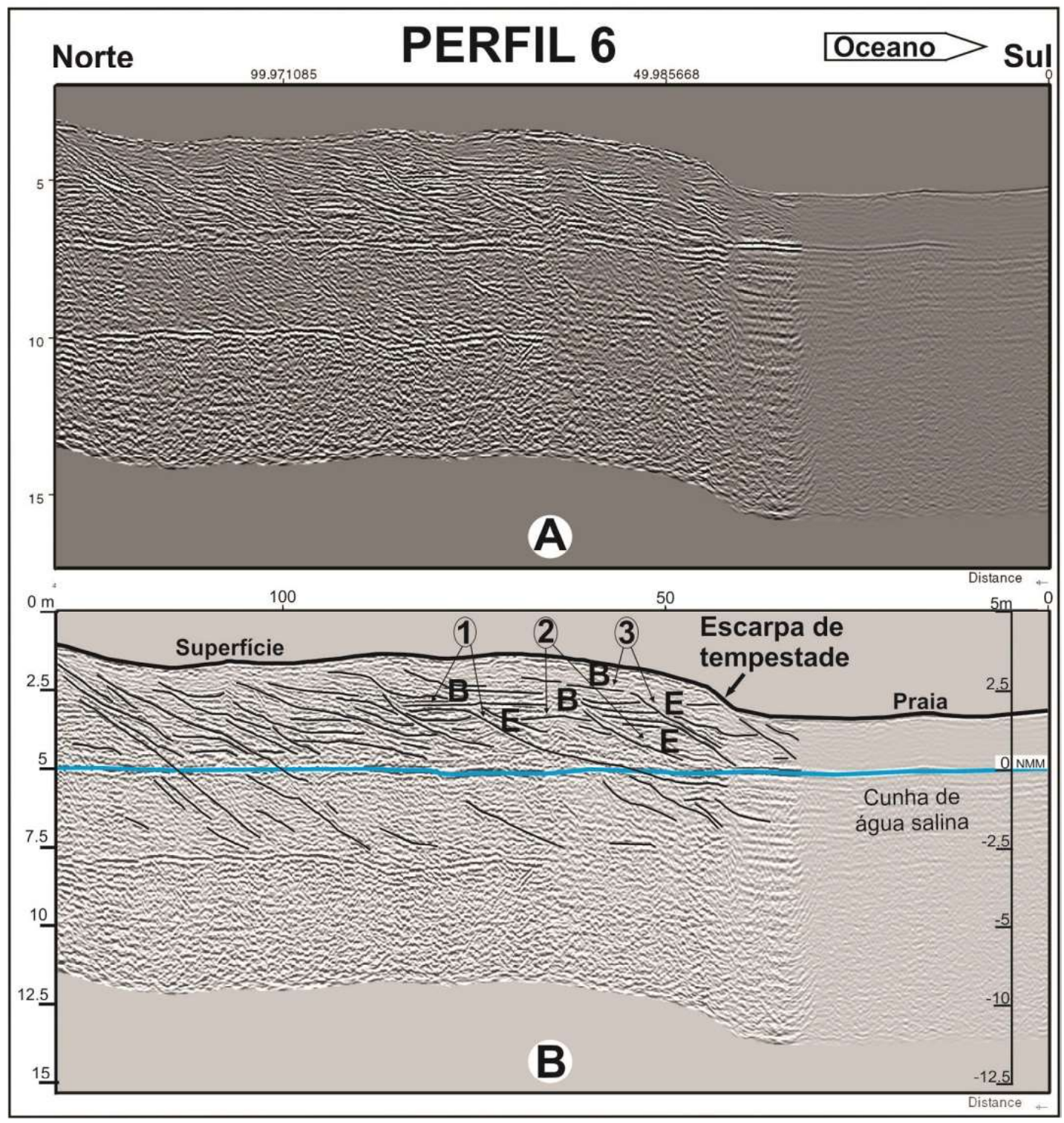

Figura 7 - Imagem de GPR, Perfil 6 de Silvestre et al. (2015), perpendicular a linha de costa, com antena de 400MHz (A-imagem não interpretada; B-imagem interpretada). Antigas (Holoceno) escarpas de tempestade (E) e bermas (B) (1, 2 e 3 indicadas por setas) aparecem como refletores relativos aos estratos plano-paralelos horizontais cortados e superficies de truncamento como refletores de formato côncavo e mergulhando para o mar. Ver figura 1 para localização do perfil. 


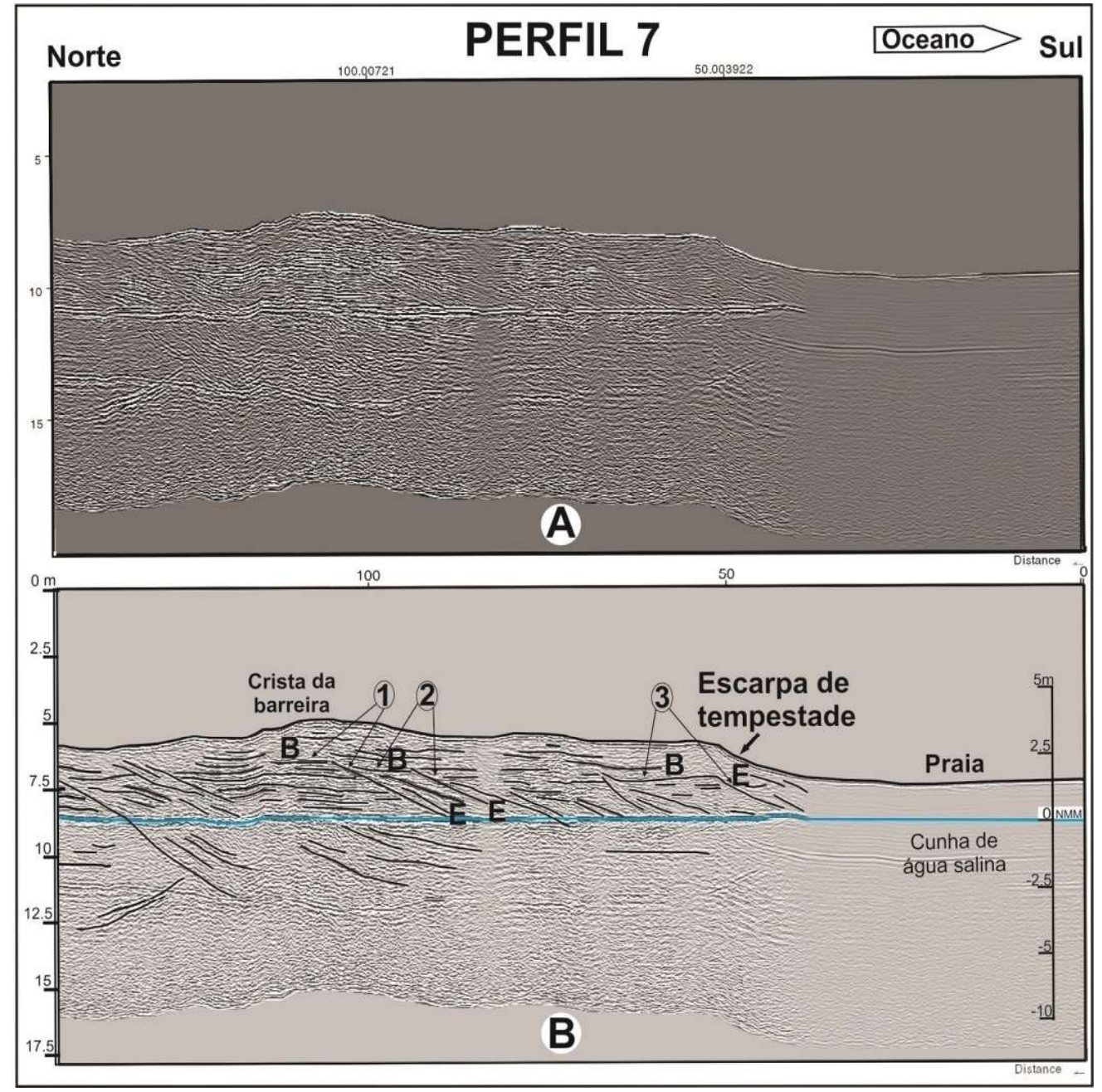

Figura 8 - Imagem de GPR, Perfil 7 de Silvestre et al. (2015), perpendicular a linha de costa, com antena de 400MHz (A-imagem não interpretada; B-imagem interpretada). Antigas (Holoceno) escarpas de tempestade (E) e bermas (B) (1, 2 e 3 indicadas por setas) aparecem como refletores relativos aos estratos plano-paralelos horizontais cortados e superficies de truncamento como refletores de formato côncavo e mergulhando para o mar. Ver figura 1 para localização do perfil.

Essas escarpas e superfícies de truncamento pretéritas ocorrem a distâncias que variam em relação ao limite interno da praia atual: ora elas ocorrem bem próximas a esse limite, ora estão a 30-40 metros a norte do limite continental da praia atual. Portanto, elas representam antigas praias pertencentes a uma barreira localizada mais ao norte. As sucessivas escarpas observadas nas imagens (Figuras 7, 8 e 9) apontam para a fase seguinte, marcada por uma progradação da barreira na direção sul ao longo do Holoceno.

Algumas das curvas existentes apresentando o comportamento do nível do mar no Holoceno (ANGULO et al. 2006; ANGULO e LESSA, 1997; CORRÊA, 1996 apud SUGUIO et al., 2005; DOMINGUEZ et al., 1987; MARTIN et al., 1987 apud MARTIN et al., 2003; SUGUIO et al., 1985) apontam, de modo consensual, para uma fase de nível do mar que ultrapassa o atual por volta de 7.000 anos atrás, alcançando o seu nível mais alto em torno de 5.000 anos AP. Como consequência, a barreira holocênica alcançou sua posição mais ao norte em torno de 5.000 anos AP (SILVA, 2011; SILVA et al., 2014b; SILVESTRE, 2013; SILVESTRE et al., 2015). Levando-se em conta as curvas de nível do mar propostas pelos estudiosos acima citados, o nível do mar entrou em uma fase de queda após 5.000 anos AP. A fase de progradação das paleoescarpas até posições próximas a atual escarpa de tempestade, observadas nas imagens de GPR (Figuras 7,8 e 9), é muito provavelmente o resultado dessa fase de descida do nível do mar, conforme já proposto por Silva (2011), Silva et al. (2014b), Silvestre (2013) e Silvestre et al. (2015). Essas são correlações tentativas, uma vez que não há datações do material que compõe tal sequência sedimentar holocênica, um problema geológico importante a ser investigado. 


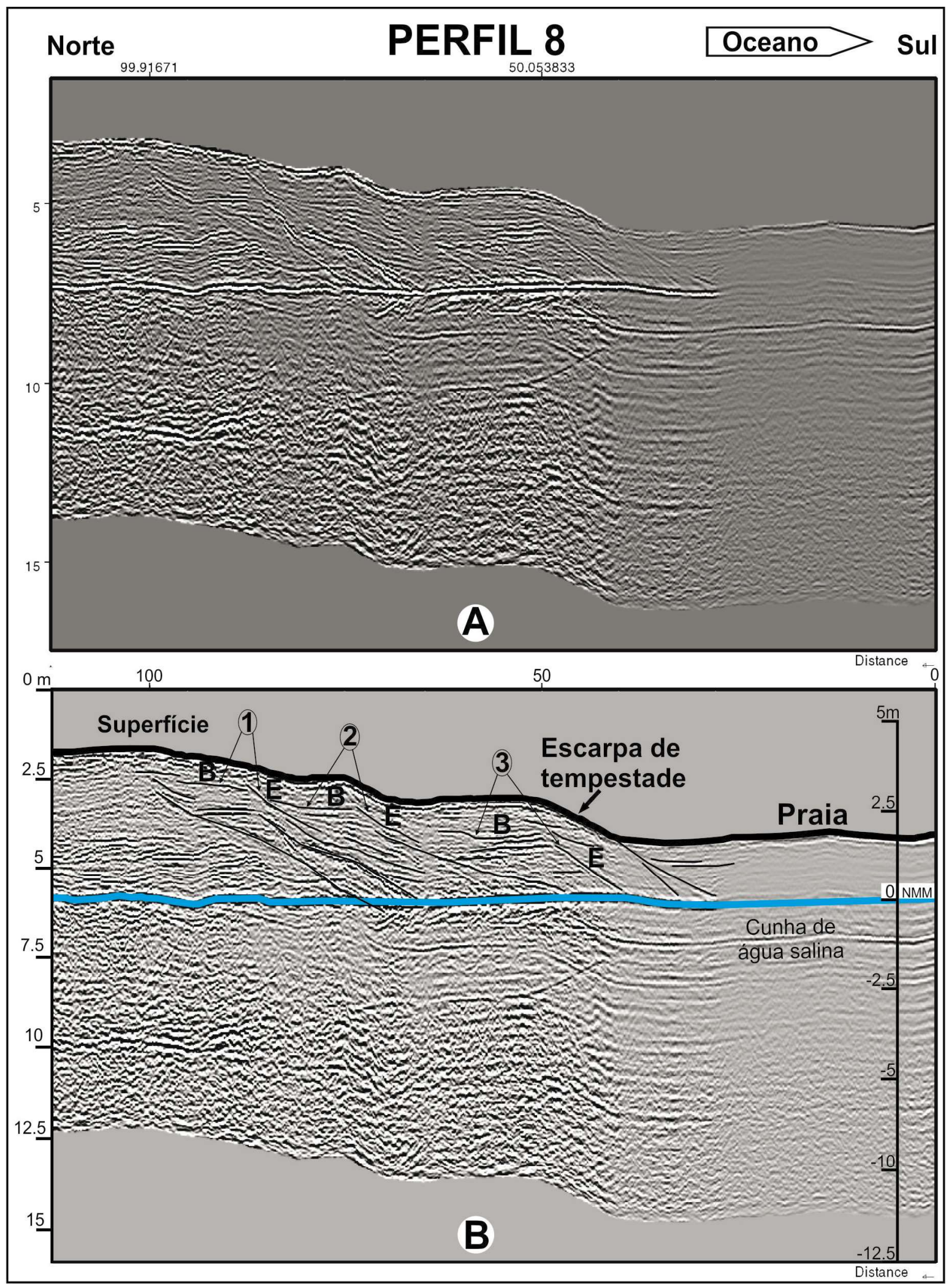

Figura 9 - Imagem de GPR, Perfil 8 de Silvestre et al. (2015), perpendicular a linha de costa, com antena de 400MHz (A-imagem não interpretada; B-imagem interpretada). Antigas (Holoceno) escarpas de tempestade (E) e bermas (B) (1, 2 e 3 indicadas por setas) aparecem como refletores relativos aos estratos plano-paralelos horizontais cortados e superfícies de truncamento como refletores de formato côncavo e mergulhando para o mar. Ver figura 1 para localização do perfil. 


\section{Conclusões}

Escarpas são feições marcantes em uma praia e são formadas pelo corte e recuo da berma quando as ondas ficam mais intensas. As escarpas maiores e mais recuadas na praia estão associadas às ressacas e são chamadas de escarpas de tempestade e podem indicar o limite interno de uma praia. Essas escarpas de tempestade e as superfícies de truncamento associadas apresentam potencial de preservação durante a evolução de uma costa, em especial daquelas progradantes, como aqui apresentado.

Neste trabalho, a caracterização e o reconhecimento das escarpas de tempestade foi feita tanto pela sua morfologia superficial observada na praia de Itaipuaçu, quanto em subsuperfície, por meio de trincheiras na mesma praia e por imagens de GPR obtidas na APA de Maricá. Geralmente, as escarpas são íngremes e sua frente é constituída por uma superfície lisa, planar ou côncava, e inclinada para o mar; essa superfície trunca as camadas plano paralelas horizontais ou sub-horizontais que formam as bermas. A altura da escarpa vai depender da altura e alcance das ondas que, no litoral estudado, pode chegar a 2 metros ou mais de altura. Essas escarpas quando preservadas se constituem em evidências que ajudam no reconhecimento de antigas praias e, portanto, contribuem para o entendimento da evolução de uma região costeira. Em Maricá, o reconhecimento das escarpas de tempestade nas imagens de GPR, muito semelhantes às observadas nas praias atuais, possibilitou determinar a evolução de um sistema barreira-laguna mais ao norte e mais distante do nível do mar atual. Essas paleoescarpas indicam uma fase de retrogradação da barreira (nível do mar relativo mais alto que o atual), possivelmente relacionado ao máximo transgressivo de 5000 anos atrás. A seguir, uma sucessão de paleoescarpas de tempestade mostra que a barreira progradou para sul, chegando a uma posição próxima àquela onde se encontra atualmente.

\section{Agradecimentos}

Ao CNPq, CAPES e FAPERJ pelas inúmeras bolsas de estudo e financiamentos das diversas pesquisas ao longo dos anos que permitiram a formação de vários estudantes de graduação, mestrado e doutorado. A todos os estudantes, colaboradores e colegas que nos ajudaram a desenvolver este trabalho nas suas várias fases, nossos sinceros agradecimentos. Agradecemos ao revisor da revista pela contribuição.

\section{Referências Bibliográficas}

ANGULO, R. J.; LESSA, G. C. The Brazilian sea-level curves: a critical review with emphasis on the curves from Paranaguá and Cananéia regions. Marine Geology, 140, 141-166, 1997.

ANGUlO, R. J.; LESSA, G. C.; SOUZA, M. C. A critical review of mid-to late-Holocene sea-level fluctuations on the eastern Brazilian coastline. Quaternary Science Reviews, 25, 486-506, 2006.

BASCOM, W. Waves and Beaches: The Dynamics of the Ocean Surface. Anchor Books Doubleday \& Company. Garden City, New York. 1964. 267 p.

BONTE, Y., LEVOY, F. Field experiments of beach scarp erosion during oblique wave, stormy conditions (Normandy, France). Geomorphology, 236, p. 132-147, 2015.

DOMINGUEZ, J. M. L.; MARTIN, L.; BITTENCOURT, A. C. S. P. Sea-level history and Quaternary evolution of river mouth-associated beach-ridge plains along the east-southeast Brazilian coast: A summary. Soc. Econ. Pal. Min. Sp. Publ., 41: 115-127, 1987.

DRM, RJ. Departamento de Recursos Minerais do Estado do Rio de Janeiro. Mapa Geológico do Estado do Rio de Janeiro. Escala 1:400.000, 1977.

EMERY, K. O. A Simple Method of Measuring Beach Profiles. Limnology and Oceanographic, Vol. 6.p. 90-93, 1961.

FRIEDMAN, G. M.; SANDERS, J. E. Principles of Sedimentology. New York, John Wiley \& Sons. 1978. 792 p.

FRIEDMAN, G. M.; SANDERS, J. E.; KOPASKA-MERKEL, D. C. Principles of Sedimentary Deposits. Macmillan Publishing Company, 1992. 717 p.

MARTIN, L.; DOMINGUEZ, J. M. L.; BITTENCOURT. A. C. S. P. Fluctuating Holocene Sea Levels in Eastern and Southeastern Brazil: Evidence from Multiple Fossil and Geometric Indicators. Journal of Coastal Research. West Palm Beach, Florida. 19, 1, 101-124, 2003.

PARDAL, M. T. da C. Mudanças morfológicas e suas implicações para a estabilidade da praia na Região do Recanto de Itaipuaçu, Maricá, RJ. 2009. 148 f. Dissertação (Mestrado em Geologia e Geofísica Marinha) - Departamento de Geologia, Universidade Federal Fluminense, Niterói, Rio de Janeiro.

SANTOS, C. L. Dinâmica Sazonal e os Efeitos das Ressacas nas Praias de Niterói (Rio de Janeiro). 2001. 151 f. Dissertação (Mestrado em Geologia e Geofísica Marinha) - Departamento de Geologia, Universidade Federal Fluminense, Niterói, Rio 
de Janeiro.

SANTOS, C. L. dos; SILVA, M. A. M. da; SALVADOR, M. V. S. Dinâmica Sazonal e os Efeitos das Ressacas nas Praias de Niterói/RJ. Revista Brasileira de Geociências. Vol. 34 (3) p. 355-360, 2004.

SILVA, A. L. C.; SILVA, M. A. M.; GAMBÔA, L. A. P.; RODRIGUES, A. R. Sedimentary architecture and depositional evolution of the Quaternary coastal plain of Maricá, Rio de Janeiro, Brazil. Brazilian Journal of Geology, Vol. 44 (2), p. 191-206, 2014b.

SILVA, A. L. C.; SILVA, M. A. M.; GRALATO, J. C. A.; SILVESTRE C. P. Caracterização geomorfológica e sedimentar da planície costeira de Maricá (Rio deJaneiro). Revista Brasileira de Geomorfologia. Vol. 15 (2), p. 231-249, 2014 c.

SIlva, A. L. C. Comportamento Morfológico e Sedimentológico do Litoral de Itaipuaçú (Maricá) e Piratininga (Niterói), RJ, nas últimas três décadas. 2006. 153 f. Dissertação (Mestrado em Geologia e Geofísica Marinha) Departamento de Geologia, Universidade Federal Fluminense, Niterói, Rio de Janeiro.

SilvA, A. L. C.; SIlVA, M. A. M.; SANTOS, C. L. Comportamento Morfológico e Sedimentar da Praia de Itaipuaçú (Maricá, RJ) nas Últimas Três Décadas. Revista Brasileira de Geociências. Sociedade Brasileira de Geologia, Vol. 38 (1), p. 89-99, 2008a.

SILVA, A. L. C.; SILVA, M. A. M.; SANTOS, C. L.; RIBEIRO, G. B.; SANTOS, R. A.; VASCONCELOS, S. C. Retrogradação da barreira arenosa e formação de leques de arrombamento na praia de Itaipuaçú (oeste de Maricá, RJ). Revista Brasileira de
Geomorfologia. Ano 9, nº 2, p. 75-82, 2008b.

SILVA, A. L. C. Arquitetura sedimentar e evolução geológica da planície costeira central de Maricá (RJ) ao longo do Quaternário. 2011. 185 f. Tese (Doutorado em Geologia e Geofísica Marinha) - Departamento de Geologia, Universidade Federal Fluminense, Niterói, Rio de Janeiro.

SILVA M. A. M. Relatório Final de Iniciação Científica, Conselho Nacional de Pesquisas (CNPQ). p. 20, 1972.

SILVESTRE, C. P. Estrutura interna da barreira holocênica e seus condicionantes geológicos (Maricá - RJ). 2013. 128 f. Dissertação (Mestrado em Geologia e Geofísica Marinha) Departamento de Geologia, Universidade Federal Fluminense, Niterói, Rio de Janeiro.

Silvestre, C. P.; SIlvA, A. L. C.; SIlVA, M. A. M.; RODRIGUES, A. R. Investigation of the internal structure and evolution of the holocene barrier of Maricá (Rio de Janeiro). Revista Brasileira de Geofísica, Vol. 33(3), 2015.

SUGUIO, K.; BITTENCOURT, A. C. S. P.; DOMINGUEZ, J. M. L.; FLEXOR, J. M.; AZEVEDO, A. E. G. Flutuações do nível relativo do mar durante o Quaternário Superior ao longo do litoral brasileiro e suas implicações na sedimentação costeira. Revista Brasileira de Geociências, 15 (4): 273-286, 1985.

SUGUIO, K. ANGULO, R. J.; CARVALHO, A. M.; CORREA, I. C. S.; TOMAZELLI, L. J.; WILLWOCK, J. A.; VITAL, H. Paleoníveis do mar e paleolinhas de costa. In: SOUZA, C. R. G.; SUGUIO, K.; OLIVEIRA, A. M. S.; OLIVEIRA, P. E. Quaternário do Brasil. Ed. Holos, Brasil, p.114-127, 2005. Site: http:/www.dictionary.com/browse/beach-scarp?s=t (acessado em 04/08/2017). Ramson House Dictionary, 2017. 